\title{
Customer Behavior and Preferences: A Survey Report ${ }^{2}$
}

\author{
Kiran Prasad Bhatta, PhD \\ Research and Program Director, Nepal Bankers' Association \\ Email: nba@enet.com.np
}

\begin{abstract}
The objective of the research is to find out the behavior of the people regarding their financial/economic activities. A survey of Banks' Customer was conducted on the selected branch inside Kathmandu valley of 28 Member Institution(s) [MI(s)] of Nepal Bankers' Association (NBA) for this research, during April to June 2010 with a sample size of 30 respondents from each Banks. Removing inconsistent data sets, however, ultimately a total of 834 data were used for the analysis.
\end{abstract}

The results showed that young, educated, salaried, man from the eastern region of Nepal with high monthly income were the major consumer of banking services provided by the MI(s). Analysis also showed that customers held a large amount of cash at hand, usually had transactions with more than one bank, and preferred the use of ATM (Automatic Teller Machine) or Debit-Cards rather than traditional instruments like Cheques. They rated the service quality and staff behavior of their banks to be of utmost importance for choosing it, followed by technological innovations, number of branches/ATMs, and other characteristics. Hence, the enhancement of service quality and pleasant behavior from staff may contribute towards client retention as well as increment in future. Technological innovation and adding up number of outlets may also help to some extent. Young generation customers are reluctant to use Cheques and had been increasingly found to use ATM-Cards, even for shopping. The trend is sure to increase more in future in the urban areas and banks should also maintain/increase providing this service for competitive necessity if not for competitive advantage.

Consumers find no specific reasons for holding large amount of cash at hand although several occasions of periodic cash shortages might have triggered this habit. Hence, efficient liquidity management on part of banks and sufficient liquidity supply by NRB (Nepal Rastra Bank) could help improve the situation. This may also help bringing back more money to the formal banking channels. Differential products and services account for only around one-fourth of reasons for having different bank accounts, but the banks could find a niche market in this regard by providing specifically differentiated products and services. Lack of awareness is also prevalent and may be one of the reasons of non-acceptance of modern technologies by some of the consumers of the financial services. Hence, customer education/awareness programs could be helpful for the banks to increase the use of latest technologies introduced by them.

2 This article has been prepared based on Nepal Bankers' Association Research Report Series (RRS\#1) paper prepared by the same author. 
Some of the customers were also found to be using the services of financial intermediaries other than the MI(s) of NBA. Less formality, less procedural hassles, high interest rate on deposits, and easy access to credit are stated to be the major reasons for using these intermediaries. Hence, reducing hassles and the length of time for processing services may help enhance the business volume of MI(s). Also, by providing higher interest rate on deposits may reduce incentives to use other financial intermediaries and help MI(s) to increase their deposit growth.

The feedback of customers include the demand for additional facilities, upgrading modern technologies, provision of quick and of international-class services, transparency in transactions with the customers, opening branches/ATMs in closures/strikes like situation, solving cash shortage problems that occurs on some specific occasions, among others. Considering these issues and implementing reasonable suggestions may help enhance the business of MI(s) and hence are recommended.

\section{INTRODUCTION}

Customer Behavior Study forms a basis for making several strategies and decisions related to a company/industry. Several researches were conducted each year just to study the behavior of customer, their choices and preferences, and the reasons associated. Rate of adoption of a newly introduced technology by the customers, customers' loyalty, customers' retention, etc are some of the issues of interest to the researchers as well as related industries. These types of research identify the behavior and response of the public towards a particular idea, technology, product, or service and are used to design the strategy accordingly.

All the industries in the west have a permanent research division as well as buy the services of consulting agencies for this purpose and there is a huge investment in this sector. However, there is a severe drought of research related to Nepalese banking sector, and the customer behavior analysis is not the exception. Usually, the need as well as effect of such research has not been identified in Nepal and the management sees no relevance of this to their businesses. Therefore, there seems a dire need for such types of researches. With the enhancement in the research related to the banking sector, the industry may acknowledge some of the critical issues highlighted by the research, practically implement these finding in their business, and could benefit from such endeavors in the long run. This research could be considered to be among the first of such kind. Besides, enhancing access to financial services as well as to increase the reach of bank and financial institutions, some sort of survey is necessary. Although, this research is focused on the consumers of Kathmandu Valley, further research must be carried out to include banks outside valley. However, even the data from this survey sufficiently showed that enhancing access to financial service is a far goal even in area like Kathmandu, which will be evident as we proceed.

\section{METHODOLOGY}

The survey was planned to cover only the MI(s) of NBA (29 at that time). However, the data represents, to some extent, commercial banks and development banks, 
public and private commercial banks, foreign joint venture banks, etc. For this research, only one selected branch (to the extent possible, head office or the main branch operating inside the Kathmandu Valley) was included. Similarly, the survey was designed to collect data from 30 random samples (respondents) from each branch of the MI. Thus, the total sample size of 870 respondents was estimated to have been collected for this research. A respondent refers to the bank's customer who visited the selected branch on the day of survey. Respondents were asked a set of questions already prepared. Semi-structured questionnaire was prepared in advance for this purpose, which was already pre-tested on a sample of around 10 respondents. However, these pre-survey test data were not used and were dumped. From the idea generated from this pre-survey, a revised set of questionnaire was modeled for the intended survey. The survey was conducted from April to June, 2010.

In course of the survey, a few samples from some of the MI(s) was missed (for example, 28 out of 29 banks were only surveyed), which was later on collected (resurvey at the end of survey was done) and completed. Again, in some of the MI(s) some additional data was collected. The additional data was selected randomly and dumped. Besides this, due to the lack of banking transactions in one of the MI(s) it was dropped from the survey, and finally a total of $28 \mathrm{MI}(\mathrm{s})$ only were surveyed. Data were collected from a total sample size of 840 respondents.

Data were entered and processed in the digital form and checked for irregularities/inconsistencies and for the missing information. Due to lack of some answers (missing information) as well as due to irregularities/inconsistencies in the answers, a few samples were dropped from the analysis. Thus, the final size used for data analysis in this research was 834 samples. Data were analyzed with the help of simple statistical measures.

\section{RESULTS AND DISCUSSIONS}

Demographic characteristics of the sampled respondents play a vital role in determining their preferences and choice. Hence, most researchers deal with this information with utmost importance. Since banking behavior and preferences also depend upon demographics of the customers, it was dealt herein (Table 1). Age, education, occupation, and several other characteristics of samples were analyzed from the available data. Average age of the respondents was found to be around 34 years. This shows that most of the customers are of young age. This might also show that relatively aged people either do not prefer or are out of the reach of formal banking channels. Strategy to bring all age groups in the banking mainstream is the need of banking sector at present. Similarly, data showed that of the total customers surveyed only around $26 \%$ are females. Although most of the female customers were approached and most of the approached ones were interviewed for this research, the low level of their representation showed that more females are still to join the formal banking system. It may also show the separate role of gender in the traditional societal system prevailing in Nepal where usually males are involved in the economic activities and outside the house-works. Despite the recent changes in the role of females including high degree of economic freedom, this research found low levels of economic involvement of females. 
Data also showed that most of the respondents are graduates (around $76 \%$ ), which again showed the abundant access of literate people in the formal banking system. Considering highest family education only $16 \%$ are non-graduates again showing dominance of educated and high class family in the formal banking system. As would be obvious, most of the respondents are either self-employed $(21 \%)$ or employed in other organizations (56\%), including both public and private organizations, with average monthly income of above NPR (Nepalese Rupees) 30,000 . As it is generally stated that the eastern part of Nepal is more advanced than the western part, data also showed higher involvement of people from the eastern part of Nepal (here eastern part is considered to be those parts that are on the east of Naryangadh-Kathmandu belt). Average family size of 5 members was also found. It should be noted, however, that this research is based only on the data collected from Kathmandu valley, which could have affected the results and may not be generalized for the whole country.

Of the respondents declaring their bank balance and cash at hand, it was found to be around NPR 200,000 and NPR 50,000, respectively. It is interesting to note that people were found to have kept a large amount of cash at hand (more than one and half times the average monthly income). This may be due to the frequent cash shortages compelling banks to reduce their cash withdrawal limits that forced people to keep a large amount of cash to meet their several needs, as will be discussed later.

The survey also revealed that around $60 \%$ of the respondents had more than one bank account, which on the average amounts to around two bank accounts per individual. Similarly, around $73 \%$ of the respondents have ATM-Cards and out of them around $46 \%$ have it for all their accounts. In this research, ATM-Cards refer to ATM/Debit-Cards wherever applicable, since almost all ATM-Cards in Nepal could be used as Debit-Cards too. Respondents answering the question on the amount of annual charges on their ATM-Cards replied that they think they pay around NPR 250 annually for this service. Most of the users are not aware of the costs associated including that for using ATM-Cards for shopping, during off-hours, etc. Out of the total respondents surveyed only around 140 respondents $(17 \%)$ had taken loans from their banks. The average loan size was slightly less than two million Nepalese rupees. 
Table 1: Demographics of the sampled Respondents

\begin{tabular}{|c|c|c|}
\hline \multicolumn{2}{|l|}{ Parameters } & Average (\%) \\
\hline \multicolumn{2}{|l|}{ Age } & 33.6 years ( 819 responses) \\
\hline \multicolumn{2}{|l|}{ Gender (Male) } & 74 \\
\hline \multirow[t]{2}{*}{ Education } & Non graduates & 34 \\
\hline & Graduates & 76 \\
\hline \multirow[t]{4}{*}{ Occupation } & Self-Employed & 21 \\
\hline & Employed on other organizations & 56 \\
\hline & Student & 15 \\
\hline & Others & 8 \\
\hline \multirow[t]{2}{*}{ Region } & East & 75 \\
\hline & West & 25 \\
\hline \multicolumn{2}{|l|}{ Average Family Size } & 4.78 Members \\
\hline \multirow[t]{2}{*}{ Highest Educated Family Member } & Non graduates & 16 \\
\hline & Graduates & 84 \\
\hline \multicolumn{2}{|l|}{ Oldest Family Member } & 55.5 years \\
\hline \multicolumn{2}{|l|}{ Monthly Income } & NPR 30579.54 (265 responses) \\
\hline \multicolumn{2}{|l|}{ Total Bank Balance } & 206316.53 (236 responses) \\
\hline \multicolumn{2}{|l|}{ Cash at Hand } & 53136.86 (137 responses) \\
\hline \multicolumn{2}{|l|}{ Have "more than one" Bank account } & 59 \\
\hline \multicolumn{2}{|l|}{ Number of Bank Accounts } & 1.77 \\
\hline \multicolumn{2}{|l|}{ Have ATM-Cards } & 73 \\
\hline \multicolumn{2}{|c|}{ Customers having ATM-Cards for all accounts } & 46 \\
\hline \multicolumn{2}{|c|}{ Cost of possessing ATM-Cards } & sponses, out of 605 ATM users) \\
\hline \multicolumn{2}{|l|}{ Amount of loans taken } & NPR 1983310 (142 responses) \\
\hline
\end{tabular}

Respondents were also requested to describe the qualities of their banks which made them choose to do business or open accounts (reasons for choosing their bank). There were several pre-specified options provided for some of the specific attributes as well as respondents were provided with options to specify their own reasons. Top ten reasons that the respondents considered to be important to choose that particular bank had been enlisted (Table 2). Around $55 \%$ of the respondents stated that the "quick service" of their bank lured them to do transaction with it. Having "ATM facilities", "pleasant behavior" of the front-desk staff, and "vicinity to residence or office", were other reasons for the choice. The results showed that people prioritize service quality first and the technology comes only after this. Besides, having many branches and ATMs are also considered to be the major factor for opting to do business with a particular bank.

Similarly, around one-fifth of the respondents feel that the reliability of the bank is important to them. Again the concept of reliability does not mean the statistical strength of a bank, class of a bank, or even the brand name. It was found that respondents that consider their bank to be R\&S (Reliable and Strong) were equally distributed among private and public banks, new and old banks (5 years was considered to be the separating line), and also between different classes of banks (that is commercial banks and development banks). Thus, even the customers from new banks and/or development banks were equally confident that they had chosen them because they felt that it is R\&S. Since, the survey does not focused on the elaboration of the concept of $R \& S$, it was difficult to understand and a new research may be required to understand what the customer actually meant by R\&S. 
Table 2: Top 10 attributes of the MI(s) preferred by Customers (Reason for choosing the $\mathrm{MI}(\mathrm{s})$ they are using at present)

\begin{tabular}{lcr}
\hline Attributes & Percent of Respondents prioritizing & Rank \\
\hline Quick Service & 55 & 1 \\
\hline ATM & 49 & 2 \\
\hline Pleasant Behavior & 38 & 3 \\
\hline Near one's residence & 34 & 4 \\
\hline Internet Banking & 29 & 5 \\
\hline Efficient Management & 27 & 6 \\
\hline Reliable and Strong & 22 & 7 \\
\hline Have Many branches & 22 & 8 \\
\hline Have many ATMs & 21 & 9 \\
\hline ABBS & 20 & 10 \\
\hline
\end{tabular}

Service usage and other behavior of the respondents were also analyzed (Table 3). Only around $34 \%$ of the respondents stated that they use Cheques on the regular basis for cash withdrawals. Adding $41 \%$ to it who use Cheques sometimes, the data showed that use of Cheques, although it amounts significantly at present, is on the decreasing trend. With the introduction of ATM, people are more interested to use this service may be due to less hassles, less queues, and ease in access. The trend thus shows that in the coming years Cheques will be gradually replaced by ATMs and will only be limited to the business transactions rather than personal transactions. As obvious, ATM users share a large portion of around $73 \%$ of the total respondents, who use this facility frequently for cash withdrawals $(91 \%)$, and sometimes for shopping (30\%). Although users of ATM have been increasing, around half of them do not know several things about it including charges (49\%). Also, the users are not updating or changing PIN number in order to protect fraud or misuse. Data showed that although the Debit-Card holders comprise a large portion of bank customers, Credit-Card is not catching up like in the foreign countries where it is the popular one. Although only $16 \%$ of the respondents were found to be using the facility of Credit-Card, it could be debated as a significant proportion given the Nepalese context. The fact that banks needs several information about the customer, a fixed income, more than a predetermined threshold, etc in order to issue the Credit-Card, it may be the reason for less popularity of this instrument. Easing up these issues may be helpful to increase the usage of these Cards. Similarly, only $17 \%$ of the respondents have been using loan facilities of banks. This may be due to the culture of general people (Nepalese public) to not consider loans as a means for investment. Although the trend has changed a lot and people nowadays opt for several types of loans to enjoy the present with the cost of future, the present number seems not to be sufficient and could be increased with effective strategy. Providing more facilities, lowering interest rates, creating awareness, and encouraging consumerism may be helpful to expand the lending services of the MI(s). 
Table 3: Use of Services

\begin{tabular}{llr}
\hline Service description & Usage data & Percent Respondent \\
\hline Use Cheques & Usually & 34 \\
\cline { 2 - 3 } & Sometimes & 41 \\
\hline Have ATM-Card & Yes & 73 \\
\hline Use ATM for withdrawal & Yes & 91 \\
\hline Use Debit-Card for shopping & Yes & 30 \\
\hline Never changed ATM-Card's PIN & Yes & 73 \\
\hline Know ATM-Card charges & Yes & 49 \\
\hline Have Credit-Card & Yes & 16 \\
\hline Have taken loans & Yes & 17 \\
\hline
\end{tabular}

Preferences of the respondents towards different behaviors related to financial activities were analyzed (Table 4). For instance, why they hold a large amount of cash at hand, why they have accounts in more than one bank, why they do not use ATM-Cards, and so on are focused. The major reasons for each query that the respondents pointed are ranked by the frequency of its repetition. In case of large amount of cash holdings, respondents opined that it is being held for daily use and emergency, although $35 \%$ of them could not figure out the exact reason. As already discussed, several instances of cash shortage in the banks may have led to such behavior of the people, since there are only $3 \%$ of cases where customers have specific purpose for the cash at hand (business transactions). Thus, NRB could play an important role in this regard to improve the situation by supplying sufficient liquidity in the market. With the confidence that they will be provided with cash on demand to an unlimited amount, the customer behavior might change to some extent and more money might come back to the banking channel rather than remaining idle in hand. Similarly, of the respondents having several bank accounts, the majority explained these as a means of making transaction easy and accessible wherever they are and whenever they need. For instance, if a person maintained accounts in several banks and put some cash in all of these the probability that he/she will be able to withdraw cash from any locations will be high since different banks have branches/ATMs at different places. Besides accessibility, business and client need is the second determining factor and the reason for $32 \%$ of respondents to hold more than a single account. Differential products and services also account for $25 \%$ of this behavior. This means that providing customers with varieties of tastes in the products and services may enhance the business volume of any bank. Respondents not having any ATM-Cards feel that they do not need it or have no specific reasons to use it. Only $10 \%$ of the respondents stated lack of knowledge being the reason for not using ATM-Cards. Special packages for ATM-users and some promotional and awareness-creating activities may help boost the use of this modern technology, may be especially targeted for middle to old-aged people, since young people had already a taste for it.

Most of the respondents that use financial intermediaries other than MI(s) stated interest rate being the determining factor. Low rate of interest in the deposit but high interest rates in lending discourages the respondents to use MI(s) and they preferred other financial intermediaries. Besides, reduced hassles, ease in access, 
and less need of formality (formal procedures) are considered major reasons for using these groups of financial intermediaries.

Table 4: Reason for Preference

\begin{tabular}{|c|c|c|c|}
\hline Parameters & Rank & Reason & Response (\%) \\
\hline \multirow[t]{4}{*}{ Reason for Cash at Hand } & 1 & Daily use & 58 \\
\hline & 2 & Others / No reason & 35 \\
\hline & 3 & Emergency & 4 \\
\hline & 4 & Business transactions & 3 \\
\hline \multirow{3}{*}{$\begin{array}{l}\text { Reason for having accounts in } \\
\text { different } \mathrm{MI}(\mathrm{s})\end{array}$} & 1 & Increase accessibility & 33 \\
\hline & 2 & Business and Client need & 32 \\
\hline & 3 & $\begin{array}{l}\text { Differential } \\
\text { Services/Products }\end{array}$ & 25 \\
\hline \multirow[t]{3}{*}{ Reason for not having ATM-Cards } & 1 & Have no reasons/Others & 43 \\
\hline & 2 & No need & 34 \\
\hline & 3 & Lack of knowledge & 10 \\
\hline \multirow{3}{*}{$\begin{array}{l}\text { Reason for taking loans from } \\
\text { individuals }\end{array}$} & 1 & Easy and interest-free & 70 \\
\hline & 2 & No formalities & 29 \\
\hline & 3 & Privacy & 6 \\
\hline \multirow{3}{*}{$\begin{array}{l}\text { Reason for depositing money in } \\
\text { Institutions other than Member BFIs } \\
\text { (Bank \& Financial Institution) }\end{array}$} & 1 & High interest rate & 59 \\
\hline & 2 & Membership & 19 \\
\hline & 3 & Easy / less formalities & 12 \\
\hline \multirow{2}{*}{$\begin{array}{l}\text { Reason for taking loans from other } \\
\text { than Member BFIs }\end{array}$} & 1 & Low interest rate & 34 \\
\hline & 2 & Easy & 31 \\
\hline
\end{tabular}

With the modernization in banking technology, MI(s) have introduced several modern and world-class technologies. However, around half of the customers lacked knowledge of one or more of these, and a strong need of awareness campaign exists (Figure 1). Among the terminologies enlisted for this survey, some seem to be entirely new to the customers. More than $60 \%$ of the customers are not aware what it means by Utility payment and EMI (Equated Monthly Installments). Similarly more than $50 \%$ feel new to SMS (Short Messaging Services) and Mobile Banking, SCT (Smart Choice Technology), and ABBS (Any Branch Banking System). Nearly half of the respondents were also unaware of Card-Systems and Internet Banking. Even the simplest like different types of deposit products, ATM, interest rate are unknown to some of the customers. The urgent need is that the banks educate their customers about such terminologies, and services they are providing to them, may be together with the associated charges in using such facilities. 
Figure 1: Percentage of customers unfamiliar with the banking terms

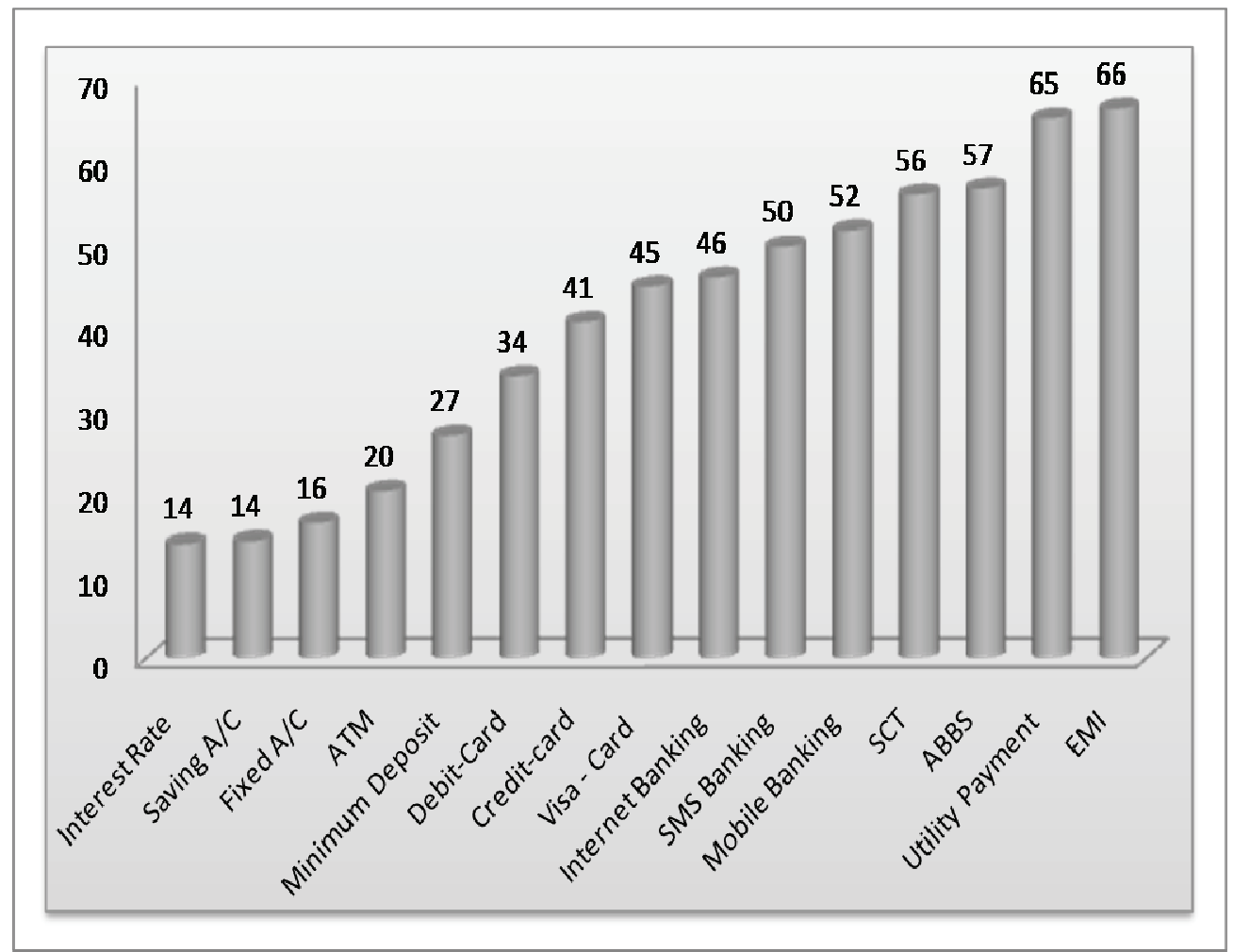

Levels of transactions of the respondents with institutions other than MI(s) are recorded in the table (Table 5). Around $9 \%$ of the respondents had taken loan from individuals (friends and relatives) as well as $12 \%$ of them had provided loans to other individuals. The average loan amount taken from individuals was around NPR 280000 and the average interest rate was around $16.5 \%$. Similarly, on the average the respondents had provided loan amounts of around NPR 300000 to individuals at the rate of $15 \%$. On the other hand, the respondents had also deposited money in the institutions other than MI(s) (12\%), with the average deposit size of around NPR 200000 and at the interest rate of around $11 \%$ on the average. Similarly, around $3 \%$ of these respondents are borrowers from the institutions other than MI(s) with the average loan size of around NPR 600000. The interest rate for these loans was found to be around $16 \%$, on the average.

This showed that interest rate on deposit from these institutions is very high compared to that provided by most of the MI(s) [although a parallel increase has been seen on interest rates of all types of institutions recently and the data may seem obsolete, but the inferences equally applies even at present]. Increasing interest rate could help bring this money and is beneficial for increasing deposit of the MI(s). Similarly, although interest rate on lending was relatively higher in these institutions but may be, as already stated, less hassles and formalities required as well as may be due to less need of collateral (or the higher valuation) may be the 
major reason for borrowing from these institutions. Changing policies to reduce hassle and expedite the process of loan processing may be important, in this regard, for the banking industry, especially for MI(s).

Table 5: Customer transaction with other than Member BFIs

\begin{tabular}{llll}
\hline Type of Transactions & Involvement & Average Amount & Average Interest Rate \\
\hline Taken loan from individuals & $9 \%$ & 279049 & $16.5 \%$ \\
& $(79$ responses) & ( 81 cases) & (29 responses) \\
\hline Taken loan from institutions & $3 \%$ & 609310 & $16 \%$ \\
other than Member BFls & $(29$ responses) & (29 responses) & (27 responses) \\
\hline Given loans to individuals & $12 \%$ & 298985 & $15 \%$ \\
& $(99$ responses) & (102 cases) & (30 responses) \\
\hline Deposit other than Member & $12 \%$ & 187961 & $11 \%$ \\
BFls & $(101$ responses) & $(102$ cases) & (98 responses) \\
\hline
\end{tabular}

As discussed already, the customers who have some sort of transactions with the MI(s) have other formal/informal banking transactions too. This may show that there was something lacking that could be improved to lure these customers to use the services of MI(s) only. With regard to the additional services/facilities required $14 \%$ stated that they wish to see additional services and features and modern technologies in the banks and opined it will increase the use of these channels up to the potential (Table 6). Besides, providing world-class services (8\%), higher interest rate in the deposits (5\%), increasing branch numbers $(4 \%)$, could be of use. Some of the respondents were of the view that indifferent behavior of bank staff, unlike staff of other financial intermediary whose behavior is quite pleasant and polite, are making them reluctant to use the services of MI(s). The respondents stated $(2 \%)$ that by making a good environment in the bank and with the pleasant behavior of staff, MI(s) could increase the number of customers. Respondents provided additional comments that could be considered by their banks to improve its quality including transparency in any transactions with the customers, provide banking services even in the case of closures and strikes, and solve the cash shortage problems in specific periods to build up confidence in the customers.

Table 6: Additional Service Requirements

\begin{tabular}{llll}
\hline Parameters & Rank & Reason & Yes (responses) \\
\hline Services needed in & 1 & Additional facilities /modern technologies & $119(14 \%)$ \\
\cline { 2 - 4 } $\begin{array}{l}\text { addition to that } \\
\text { available in one's bank }\end{array}$ & 2 & Quick and world-class services & $66(8 \%)$ \\
\cline { 2 - 4 } & 3 & Higher interest rate & $39(5 \%)$ \\
\cline { 2 - 4 } & 4 & More branches & $33(4 \%)$ \\
\cline { 2 - 4 } & 5 & Pleasant behavior & $15(2 \%)$ \\
\hline Additional comments & 1 & Need of transparency & $59(7 \%)$ \\
\cline { 2 - 4 } for one's bank & 2 & To be opened on Closures/Strikes & $18(2 \%)$ \\
\cline { 2 - 4 } & 3 & Cash shortage problem should be solved & $8(1 \%)$ \\
\hline
\end{tabular}

\section{CONCLUSIONS AND RECOMMENDATIONS}

The analysis of data obtained from the survey showed some interesting aspects of the banking industry. Most of the customers of the MI(s) are young aged, male, graduates, employed with high income levels, and from the eastern region of the Nepal. This may reflect the people residing in the Kathmandu valley but certainly 
something could be done to increase inclusion of other groups of people. Schemes attracting aged people, females, less literate, and low income families, could enhance the banking activities, enhance its reach to the untouched segment of the society, as well as could be a part of CSR (Corporate Social Responsibility) of the MI(s). The situation must be worse outside Kathmandu valley and hence consideration needs to be given in this regard.

Research also pointed toward the increasing trend of people to keep a large sum of cash at hand. The people may have been provoked by the cash shortages in the recent periods, especially when it is a must (needed), like during the festivals. Compared to the monthly income, cash at hand is around one-and-half times the sum, and compared to the bank balance it is around one-fourth, all indicating a large sum of cash out of the banking system. Adding the under-economy money the amount could be guessed to be surprisingly high. The liquidity crunch in the last year may also be the effect of this situation. Policy to bring back the large portion of this money is outside the scope of this research, however, government could envisage some policy that could be of some help. Also, building confidence in the customers may cut down the habit of holding large amount of cash without purpose. NRB as well as banks could play a positive role in this regard. NRB should take a stock of currency supply and prepare for the future, while banks should also effectively manage its liquidity.

Regarding the reason for preference of their banks most customers acknowledged their service and efficiency. Technology comes next to it, may be because most of the banks are providing somewhat similar services and technological products (there is less differentiation in the products and services). Having many branches and ATMs is also a competitive feature to attract a large number of customers. One-fifth of the customers also pointed out towards the reliability and strength of their banks to be the determining factor for choosing any particular bank but given that customers from all types of banks presume their banks to be R\&S, it is difficult to assign the features of banks to be R\&S. Further research may be needed to find out exactly what this term means to a customer.

With the popularity of ATM-Cards (of course ATMs too) customers using this facility has increased tremendously comprising around three-fourth of the respondents in this survey. Cheques had been gradually replaced by ATM-Cards and may be in 510 years they may be limited to business transactions or some similar cases. However, at present its importance has not decreased and around three-fourth of the respondents use it at least in some occasions. On the other hand, use of CreditCards has not been much extensive may be due to several reasons peculiar to Nepalese context unlike in developed countries where Credit-Cards are highly popular (saying differently Debit-Cards are rare). One of the reasons is related to weak law enforcement in Nepal leading to high level of frauds in case Credit-Cards were provided without proper counter-measures. This compels banks to limit issuance of Credit-Cards only to people with high income levels, well-paid and permanent job holders, and with other similar characteristics. MI(s) could consider loosening some of the criteria to popularize its use as well as government could play a vital role by enhancing law enforcement. 
Similarly, loans are also not so much popular in Nepal compared to developed countries where almost everybody takes loans to enjoy the present. Yet the situation has improved compared to past when people hesitated taking loans and one who take loans were considered to be financially bankrupt. While the trend is increasing, banks should focus on policies to increase consumerism, provide loans on reasonable interest rates, reduce hassles and long procedures, and create public awareness to enhance their business. The case is similar with the ATM-Cards: most customers do not feel they need it. Awareness creation and education of customers is required in this case, which is more important under the current circumstances when around half of the customers were not aware of several terminologies, and products and services of the banks.

Some of the customers are also involved in financial transactions with other types of financial intermediaries. The major reasons for this are less hassles and formalities for loan processing, higher interest rates on deposits, aggressive approach of these institutions to attract customers, and so on. To compete with this, banks should lower the spread, reduce hassles and expedite the process, and adopt different approach for deposit marketing. Besides, banks are seen to be ignoring low level income groups (the major customers of other institutions), which when combined could form a significant volume of business. As is the case of SMEs in the past, approach to involve this segment of people may enhance the business of the banks in a sustainable manner. Pioneering in this regard may have a competitive advantage (although a few commercial banks had recently started somewhat similar products, the true picture is yet to be seen).

Respondents taking part in this survey had also demanded several additional facilities and updated technologies to be available in their banks. They also felt that there is some space for improvement in the quality of service provided by their banks. Increasing service efficiency, pleasant behavior, higher interest rates on deposits, more branches and ATMs are other features they wish to see in their banks. Besides these, customers need transparency in the procedures while dealing with them, which may also mean more educational/awareness need to them. They also wish to see their banks opened in closures/strikes and their banks not limiting cash withdrawals.

Since, this research is the first of this kind and a preliminary one, it recommends several such researches based on a single issue related to consumer behavior for examples towards a single technology and products etc, and also that improves the weakness of this research. 